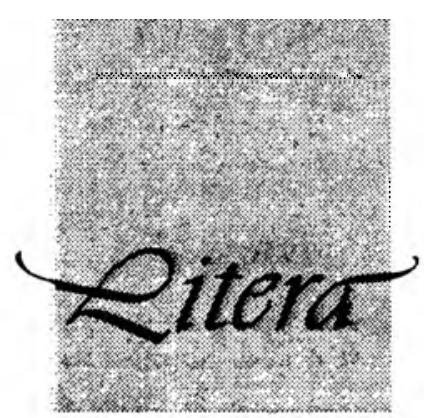

Hans du Plessis
Begrafnis

153

Rubriek vir skeppende werk

Met die afdeling Litera tree ons toe tot die mark vir skeppende werk in al die tale waar daar normaalweg in Literator geskryf word.

Dit is die wens van die Redaksie dat die gedigte en kortverhale wat hierby verskyn, baie gedigte, kortverhale en prosa- en dramafragmente in ander inheemse tale sal roep, sodat hierdie blad én geïntegreerde beeld van die korter skryfwerk van jong Suid-Afrikaanse skrywers kan bied.

Dit is met vreugde dat ons die uitnodiging aan veral digters en kortverhaalskrywers rig om skeppende werk voor te lê vir plasing in hierdie rubriek, met die voorbehoud dat ons nie oor die mannekrag beskik om daaroor te korrespondeer nie. Bydraes in viervoud moet in dubbelspasiëring getik wees, met die naam en adres van die insender regs bo aan die eerste blad van gekramde tekste en op elke losbladvel wat gestuur word.

Stuur alle bydraes aan Die Hoofredakteur, Literator (629), Buro vir Wetenskaplike Tydskrifte, Privaatsak X6001, Potchefstroom 2520.

\title{
Section for creative writing
}

In introducing the section Litera we are entering the market for creative work in all the languages that Literator normally caters for. It is the wish of the Editorial Board that the poems and short stories printed in this issue will only be the precursor of many poems, short stories, prose and drama fragments in all the indigenous languages, so that the journal will be able to present one integrated image of the short pieces of writing which young South Africans can offer.

It is with great joy that we extend this invitation to especially poets and short fiction writers to submit creative work with a view to publishing them in this section. The only reservation is that we do not have the manpower to enter in to correspondence about the works submitted. Four copies of contributions have to be submitted. The submissions have to be typed in double spacing, with the name and address of the author at the top right of the first page of stapled text, and on every loose sheet sent in.

Send all contributions to the Editor-in-Chief, Literator, (629), Bureau for Scholarly Journals, Private Bag X6001, Potchefstroom 2520. 
Hans du Plessis

\section{Begrafnis}

"Dis nou vir jou 'n tyd om te staan en doodgaan." Koos gaan sit swaar in die stoeltjie met die ligroos stoffering. Dat die gestoeltetjie onder sy swaar bas op fyn pootjies bly staan, is 'n wonder. Hy steek sy soveelste sigaret op.

"Sy kon 'n beter tyd gekies het," antwoord Jan en kyk by die venster uit. Iewers buite borrel 'n vleiloerie.

"Dis julle ma wat julle van praat."

"Joune ook, boetie Frans, joune ook." Koos glimlag effens. Die drie broers bly sit, elkeen met sy eie gedagtes. In die woonkamer slaan die oorlosie elfuur - 'n oorlosie wat hulle oorlede pa nog as geskenk gekry het toe hy die kerk se klaskamers verniet gebou het, destyds voordat dit so goed met hulle begin gaan het, voordat hulle nog die plaas gekoop het.

"Hel," begin Koos weer, "om nou 'n end te wil kry dié tyd van die jaar. En nou sal ons seker weer almal moet afkarring plaas toe vir 'n lekker ou Boerebegrafnis, en die ou spul sal seker nog verwag die seuns moet die gat toegooi. Hel." Hy staan swaar op uit die stoeltjie en gaan voor die venster staan met sy rug na die ander twee toe. Hulle antwoord hom nie min mense antwoord Koos van der Merwe omdat antwoorde hom in elk geval nie interesseer nie.

"Kan ons haar nie maar hier in die stad begrawe nie?" Frans vra dit versigtig, amper fluisterend. Hy roer nie, bly op diesefde blom in die patroon op die groot persiese mat kyk. Hy kyk ook nie op as nie een van die ander twee reageer nie.

"Dis 'n moontlikheid," antwoord Jan sonder dat iets in sy gesig se uitdrukking verander. "Ek sien wragtag nie kans vir die bosveld se plat hitte nie - nie in November nie."

"Ons sal haar hier in die stad begrawe." Koos draai van die venster af weg en loop in die deur byna in die swart vrou met die silwer skinkbord vas. "Sit maar neer, Johanna. Sit neer die tee." Sy sit die skinkbord op die donker halfronde tafeltjie teen die muur. Die silwer teepot en die fyn koppies weerkaats in die groot spieël teen die muur. Johanna loop sonder 'n woord weer uit. Frans begin die tee skink. Hy kyk om as hy Jan uit die hoek van sy oog sien opstaan, maar kyk weer waar hy skink. Jan trek net aan een van die skilderye teen die muur sodat dit weer reguit hang.

"Ek sal laat reël." Koos sien nie eers die koppie tee wat Frans na hom uithou nie, hy loop uit en die twee in die sitkamer hoor hom donderend na sy vrou roep. Frans bied Jan nie ' $n$ koppie tee aan nie, hy vat sy eie en loop sit. Jan kry sonder 'n woord 'n koppie tee. Dis stil, behalwe vir die laksman wat buite iewers in die hitte suis.

"En nou?" vra een van die twee vrouens wat by die sitkamer inkom. 
"Ons sal Ma maar hier in die stad begrawe, Rita."

"Dit is nie wat sy sou wou gehad het nie! Ons kan nie, dit is nie reg nie."

"Miskien, ou Willenmientjie." Jan staan op en raak net effens aan sy vrou. "Maar jy weet self hoe 'n besige tyd van die jaar dit nou is. Dit kan nou nie anders nie."

"Ek bly dink dis verkeerd," sề Rita en skink twee koppies. "Drink jy steeds nie suiker nie, Willemien?" Sy gee die koppie aan.

"Steeds nie. Dankie." Die vier drink hulle tee in stilte. Buite hoor hulle Koos se motor by die hek uit ry.

"Koos sal laat reël," sê Jan, maar niemand antwoord hom nie. 'n Mens kan hulle hoor drink.

So is die begrafnis van Johanna Elisabet Maria van der Merwe dan gereël vir 29 November 1985 om tienuur die oggend uit die NG kerk, Kandelaar, Linden, Johannesburg.

En dit was 'n mooi begrafnis, net jammer van die swart vrou.

Jy sal seker die koerant onthou, die een van Saterdag, 2 Desember:

\section{SWART VROU UIT KERK GEJAAG}

Die grafsteen was iets besonders:

In tere herinnering aan ons dierbare moeder JOHANNA ELISABET MARIA VAN DER MER WE

Sy het haar lewe aan haar seuns gewy

Gebore 6 April 1905 Oorlede: 28 November 1985

As Koos van der Merwe iets organiseer, is daar nie plek vir foute nie. Van ou Sielie kon hy tog nie vooraf weet nie.

"Ek hoor hulle gaan die oumiesies in Johannesburg bêre."

Hulle sit buite in die koelte van die maroela. Sielie Rantho vee 'n keer oor haar oë met die sakdoek wat sy weer in die wye voorskoot se sak sit.

"Gaan jy soontoe?" Maria Mahlango gooi die stuk wit linne waarop sy sit en borduur met een geoefende swaai 'n ent verder oor haar knie, sy kyk nie van haar naaldwerk af op as sy praat nie. 
"Ek sal moet loop. Ek het dertig jaar vir die ou mens gewerk, en ons was goed gewees vir mekaar." Sielie sit voor haar op die stowwerige grond en kyk, tel 'n stokkie op en krap daarmee langs haar in die grond, asof sy iets in die stof wil skrywe.

"Johannesburg is mos ver?" vra sy, maar gaan dan aan, sonder om vir 'n antwoord op haar vraag te wag: "En die treinkaartjie sal seker baie wees, maar ek sal maar moet gaan. Die oumiesies was goed gewees vir my. Ek kan nie laat sy alleen gebêre word nie."

"'n Treinkaarrjie is duur. Johannesburg is nie hierso nie, dis ver."

"Ek sal maar die geld in die trommeltjie moet vat." Sielie sug.

Dit is die eerste keer dat Maria van die naald se punt af opkyk: "Jy kan dit nie doen nie! Jy het swaar gespaar."

Almal weet van die trommeltjie met die geld in: sy spaar dit al oor jare vir Leratho se opvoeding. Almal weet: sy wil Leratho laat leer, vir 'n dokter.

"Nee, Suster," begin Maria en die naald hang stil bokant die borduurwerk, "ons sal almal 'n bietjie kan help. Jy kan nie die spaargeld vat nie."

"Vir wat spaar Ma die geld al die jare?" Die twee vrouens het eintlik al vergeet dat Leratho naby hulle op die stomp sit, hy het tot nou toe nie gepraat nie, en hy kyk ook nie na sy ma as hy die vraag vra nie. Dit lyk amper asof hy met sy kop tussen sy knieë sit.

"Jou ma spaar die geld vir jou sodat jy geleerd kan wees."

"Geleerd? Om te wat? Wat sal ons nou in hierdie land met geleerd wil maak? Jy kan hoe geleerd wees, dit sal jou niks help nie. Ons soek vryheid, nie geleerdheid nie."

"Jy is nog te jonk om te verstaan, Leratho," sê Sielie.

"Verstaan die wit mense ooit? Vir wat wil Ma begrafnis toe gaan? Vir 'n wit mens? Ek kan daai geld baie beter gebruik. 'n Mens kan vir die kaartjie se geld 'n geweer koop hier anderkant." Leratho staan op, loop onder die maroela se skadu uit in die helder, witwarm dag. Hulle sien hom wegstap.

"Eendag sal hy verstaan." Sielie sê dit eintlik vir haarself, maar Maria antwoord.

"Miskien. Ons sal maar almal saam maak vir die kaartjie. Moenie die trommeltjie se geld vat nie."

"Dankie, Maria." Sielie soek na die sakdoek in die voorskootsak.

Dit is vieruur die oggend as Sielie sukkelend van die krakerige bedjie af regopkom. Sy trek in die donker ritselend aan, en sy hoor die munte teen mekaar kap as sy die Black \& White-twaksakkie uit die kombuiskas haal. In die bietjie lig kan sy die oorlosie in die boonste middeldeurtjie van die koskas se wysters sien, dit loop lankal nie meer nie, maar die wysters glim nog plek-plek waar die fosfor nog nie af is nie. Sy lig die dun deurtjie met 
die oorlosie op. Die bliktrommeltjie is nog daar. Die deurtjie klap hard as sy dit los. Sy loop, voel of die twaksakkie goed toegeknoop is.

Die son is nog net 'n skynsel as sy die vuur onder die maroela aanblaas, die as is nog warm. Sy skink vir haar 'n klein bietjie koffie as die water sing.

Dan loop sy onder die groot maroela uit, en verder weg maak 'n fisant die oggend raserig wakker. Dan is sy onder die boom uit. En sy is alleen, onthou net die reuk van die sekelbos wat agter haar nog effens gloei. Dan loop sy. Dis al warm so vroeg in die môre.

Johannesburg. Sy sug, voel na die twaksakkie by haar bors onder die rok ingedruk. Sy lyk al klaar moeg as sy eers die voetpad en dan die rooi plaaspad tussen die bome deur vat. Sy lyk netjies in die swart rok met die wye wit kraag.

"Sewe en twintig rand agt en veertig sent," sê die man agter die kopertralies. Sy hoor nie, verstaan nie mooi nie.

"Ek sê: die kaartjie Johannesburg toe is R27.48. Is jy dan doof, of het jy weer te min geld? Ek het nie heeldag tyd nie."

Haar hande bewe as sy die knoop van die sakkie probeer los maak. Sy weet nie: sou daar ooit soveel in wees? Sy gooi die munte op die toonbank uit, en bly so staan sonder om iets te sê. Die man agter die toonbank sug, vee die hoop geld met sy groot, wit hand nader en begin tel. As hy klaar is, stoot hy die kaartjire en 'n hopie van die geld terug. Sielie bly voor die toonbank staan, gooi die kleingeld terug in die sakkie en sit dit en die kaartjie weer voor by haar rok in. Die man agter die toonbank staan haar en aankyk, maar hy of sy praat nie een nie.

Sy wys die verkreukelde stukkie bruin papier vir die eerste polisieman wat sy net buite die gewoel van die stasie raakloop. Dit is die enigste ding wat sy tussen die duisende gesigte en malende voete herken: die blou uniform. Hy frons en bekyk die papiertjie in haar hand. Sy oë is dan stip op haar en hy kyk weg, ver oor die mense om hulle. In die skewe letters van die voorstad se naam, die amper onleesbare straatnaam en in haar oë kan die wit polisieman die krom ou mens se alleenheid lees, hy luister na haar stom roep om hulp. Hy Ioop voor haar uit en sy skuifel agter hom in.

"Kom," is al wat hy sê. By die busstop praat hy met 'n vrou in 'n groen oorrok en 'n helder geel kopdoek. Sielie hoor nie wat hulle sê nie, maar sy sien hulle lippe en weet dat hulle oor haar praat.

"Kom, ek sal jou help, Mma." Die groen vrou met die kopdoek vat haar aan die arm en trek haar voor haar in die ry in.

Die bus stop en sy voel hoe sy ingedruk word in die klein keelgat van 'n bus wat swart staan en rook.

Sy verlang na die reuk van skoon rook van 'n sekelbos. Sy is dors vir die water uit die fontein. Van vanoggend af het sy nog nie gedrink of geëet nie - die geld is vir die kaartjie, nie vir eet nie. Die sluk is droog. 
Sy sit skuddend tussen die vrou met die kopdoek en 'n man met 'n hoed op. Sy praat nie: die praat bly agter die knop in haar keel sit.

Pare hande wat verstaan, help haar by 'n busstop af. Sy staan op die sypaadjie, skrik vir die spoed van die baie karre. Dan kyk sy op en sien die kopdoek agter die bus se venster. Die bus ry al as die venster oopskuif.

"Loop mooi, Mma! Die kerk is in hierdie straat. Bly net loop, jy kan hom nie misloop nie. Die toring staan hoog met 'n hoender op sy punt."

'n Hoender! Dit ken sy, en sy loop.

Sy bly buitekant die kerk met die hoender staan totdat almal in is. Dan sluip sy by die groot deur in en gaan agter teen die muur staan. Sy sien die seuns in die voorste ry sit. Dankie, Here, ek is op die regte plek. Dankie!

"Daar's 'n meid in die kerk." Die fluister wip van bank tot bank, en die stilte wat daarop volg is oorverdowend.

Sy luister as die man in die swart klere kom vra dat sy buite moet wag.

Sy wag.

As sy hulle Nader my God hoor sing, vat sy eers die twaksakkie raak voordat sy die sakdoek in haar hand voel.

"Die oumiesies is dood. Sy was so goed vir my, Kleinbaas, Frans." Sy ken iemand!

"Ou Sielie! Hoe kom jy hier?"

"Ek het die trein gevat."

"Baas Jan is hier met die bakkie. Ek sal hom vra om jou op te laai. Moenie tussen die mense staan daar by die graf nie. Dis goed jy't gekom, ou Sielie."

Toe almal weg is, vat sy die handjievol rooigrond en laat dit ver onder op die blink hout val.

"Tot siens," sê sy.

Die twee swart mans bly op hulle grawe leun totdat sy klaar is, en hulle wys haar die pad busstop toe, en hulle verduidelik mooi waar sy die stasie se afklim gaan kry. "Dis maklik," sê hulle, "jy ry net totdat die bus nie meer verder kan gaan nie, Oumatjie."

Sy loop, draai een keer om om te sien hoe die mans die gat toegooi.

"Hoe was dit toe?" Maria staan op toe sy Sielie sien aankom.

"Dit was 'n mooi begrafnis gewees, Maria. Ons het die oumies gebêre." Sielie gaan op die klip naby die maroela se stam sit, en sy drink en drink uit die groot blikbeker met die koel 
water. Dan sit sy die beker neer, trek die twaksakkie uit en gooi die kleingeld in haar hand uit.

"Hier is die geld wat oor is. Waar is Leratho?"

Niemand antwoord dadelik nie. Lank nadat die vraag uit die lug se warm vuis geval het, sê iemand: "Hy is net na jou weg."

In die skemer kamer klap sy die deurtjie met die dooie oorlosie oop. Die trommeltjie is weg. Sy bly so met die deurtjie in haar hand staan totdat sy iemand agter haar hoor. Sonder om om te draai, praat Sielie:

"God vergewe hom, Maria. Hy is nog jonk genoeg om te haat."

"Het jy die brief in die koerant gesien, Jan?"

"Nee, wat staan daar?" Jan kom langs Frans van der Merwe staan waar hy met die koerant voor hom oop op die tafel sit.

"Dis broer Koos wat daai liberale brief van nou die dag antwoord. Hy sê hom goed. 'Dit gaan nie oor kleur nie,' skryf Koos. 'Dit gaan oor die behoud van die eie.' Goed ons het Koos maar laat skryf."

"Ek het mos gesê dit was 'n verkeerde tyd om te staan en doodgaan." 